\title{
The architecture of a mesoscopic model of the real- time transport corridor in projects of intelligent transport system
}

\author{
Alexander Shemyakin \\ Department of Organization of \\ transport processes and life safety, \\ Ryazan State Agrotechnological \\ University after P.A. Kostychev, \\ Ryazan, Russia \\ shem.alex62@yandex.ru
}

\author{
Anton Kuraksin \\ Department of Organization of \\ transport processes and life safety, \\ Ryazan State Agrotechnological \\ University after P.A. Kostychev, \\ Ryazan, Russia \\ aakuraksin@gmail.ru
}

\author{
Anna Mikhailova \\ Department of Construction Economics \\ and Housing and Utility Infrastructure \\ Saint Petersburg State University of \\ Architecture and Civil Engineering \\ Saint Petersburg, Russia \\ anneym@mail.ru
}

\begin{abstract}
Accelerating development of cities and global urbanization process lead to increasing the transport domain importance that is especially actual within the framework of making the "smart city" concept, one of the main elements of which is the widespread use of digital technologies to improve the road traffic safety. As a result of the authors' study, a mathematical apparatus for assessing the transport corridors performance was proposed, on the basis of which it is possible to integrally approach the assessment of the traffic quality in the project implementation area of the smart transport system. On the basis of a mesoscopic simulation model, performance indicators of the transport corridor were obtained in the central part of Ryazan. The paper's authors proposed a methodological technique for the formation of a simulating field taking into account possible routing paths in transport corridors, as well as they presented a description of the simulation software package and the general architecture of the developed system. As well as the paper presents a software system prototype for visualization of the calculated indicators in the transport model; architecture of real-time data handling; description of a monitoring system based on Bluetooth and WiFi technologies to be implemented to generate real time dynamic correspondence matrices.
\end{abstract}

Keywords-corridor network management; DTAlite/NEXTA; transport model traffic management efficiency; dynamic assignment model; DTA modeling

\section{INTRODUCTION}

Due to the high cost of road infrastructure facilities construction, extensive measures are often taken to develop urban transport systems to be implemented through more efficient traffic management. In the nearest future, traffic management strategies can be described as user information systems including dynamic signs and displays, mobile applications, radio messages for drivers, etc. The control systems will include reversible lanes, charging systems, adaptive coordinated control at sets of traffic lights using detectors, access control system for the road network (RNW), etc. Among the decision support systems in traffic conditions, computer simulation of the transport situation, adaptive control calculation systems at sets of traffic lights, incidents monitoring systems in the transport network, etc. will be distributed.
As a result, the above systems are combined into specialized subdomains of intelligent transport systems (ITS). The very concept of an intelligent transport system does not have a single definition; the experts interpret it differently. The paper's authors present the basic concepts and architecture of the ITS [1] developed on the bases of the Moscow Automobile and Road Construction State Technical University (MADI). Komarov V.V. considers foreign experience and domestic practice of ITS projects implementation in his study [2].

Currently, the ITS projects have achieved significant development, more and more often they use highly accurate on-line data on operation of transport systems based on FCD, Bluetooth, RFID and other technologies for real-time exchanging traffic data. Thus, real-time traffic data, which can be interpreted into traffic forecasts in order to improve information support for road users, has become the most important information for the ITS. However, despite the development of individual elements of the ITS, it is necessary to establish links between the set of data obtained in the real time mode and their actual application when arranging traffic management [3]. In most cases, this situation is explained by the difficulty to combine a significant amount of information and the imperfection of the methods to use the current technique of mathematical simulation of traffic flows. A number of scientific issues related to the type design of models that allow simulating the traffic situation in sufficient detail to forecast a level of traffic congestion and performance indicators of road networks remains open. Thus, the problem for studying models and architecture of real-time traffic flows simulation is extremely relevant in modern social and economic conditions. This paper is aimed at clarifying approaches to choosing the optimal architecture when simulating and analyzing the performance of traffic networks, which can be used to improve the ITS.

\section{SOURCES REVIEW}

The problem of traffic flows description was studied by such scientists as Lighthill M., Whitham G. [4] dealing with the traffic flows theory, Newell G. F. [5-7] who has developed in detail the kinematic theory of traffic flow. As a 
result, currently, the integrated applications for traffic flows simulation have been developed based on these studies,

Among modern researchers dealing with the problem of traffic flows simulation in the ITS networks, we can distinguish such foreign scientists as Zhou X., H.S. Mahmassani. Among the large number of studies conducted by the authors, we can distinguish the papers devoted to the dynamic micro simulation of traffic flows [8], real-time correspondence matrix estimation [9], and equilibrium analysis for dynamic flow distribution [10].

Among Russian researchers, the papers of such scientists as V.V. Zyryanov and Zhankaziev S.V. are known. Zyryanov V.V. carried out the studies for assessment of the transport models adequacy [11], selecting a route for dynamic redistribution of flows [12], analyzing and systematizing data on incidents in the road networks [13]. Zhankaziev S.V. studied the principles for forming the architecture of the local ITS projects [14], and also formed the basic concepts of the ITS systems building in Russia [15].

It is also worth highlighting studies on the systematization of data by types of transport models [16], the identification of general trends and approaches to modeling flows in real time. A detailed analysis of applications for traffic flows simulation is presented in the study [17] including the attention paid to simulation modeling in ITS projects.

A significant contribution to research on the use of various types of traffic flows simulation in ITS projects is made by the US Department of Transportation. Among the large number of funded studies aimed at the traffic flow simulation, the project "Testbed Development and Evaluation to Support Dynamic Mobility Applications and Active Transportation and Demand Management Programs" can be distinguished. This paper is devoted to various applications that allow simulating traffic flows in ITS systems. The project included the following cities San Mateo, Pasadena, Dallas, Phoenix, Chicago and San Diego. Among the studies, one can distinguish the papers that are carried out by PTV Groupe (product PTV Optima) [18] and TSS Aimsun (product Aimsun Online) [19] within the framework of their internal scientific research.

\section{MATERIALS AND METHODS}

The general methodology for building a real-time mesoscopic model of transport corridor is based on a number of important elements: simulation area formation, determination of transport-analytical and boundary areas, development of routing cases and choice of a flow description model, development of a simulation software package, creation of an information architecture from a set of peripheral devices and systems used for processing the obtained data.

At the first stage of model building, a simulation area is formed. The area choice should be based on an analysis of possible routing paths for various network incidents. As well as this area shall be featured by low traffic capacity of the road network, the presence of incidents leading to congestion, an assessment of the routing potential is necessary. On the other hand, the simulation area shall be compact due to the fact that the territory shall be tightly covered by peripheral devices, allowing real-time calculation of correspondence matrices and calibration of the dynamic model. Further, the various boundary zones between which trips are made shall be determined by the selected area. This includes the so-called transport-analytical zones, as well as zones located at the borders of the simulation area. These zones are the main boundaries for implementation of the mesoscopic model of the real-time transport corridor.

As mentioned above, the general concept of the mesoscopic model of the real-time transport corridor shall satisfy the routing criterion. This means that additional ways, where traffic can be redirected, shall exist in case of the events that sharply reduce the efficiency of transport corridor use. Figure 1 shows an example of two routes in the studied zone.

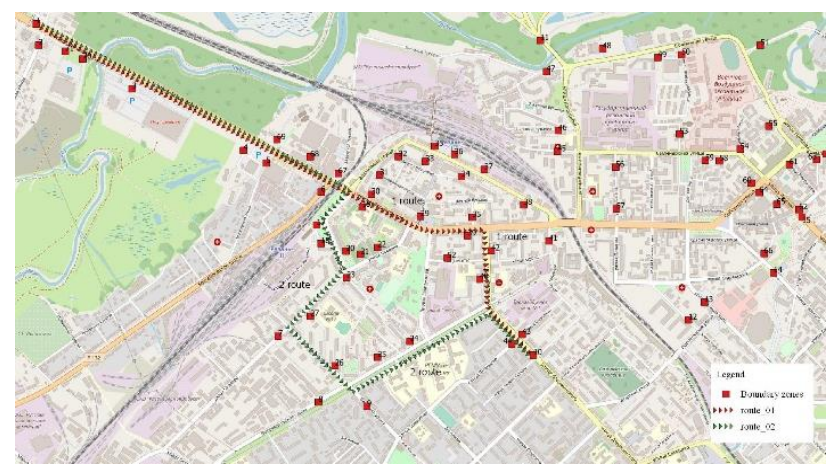

Fig. 1. The example of traffic flow routing in the mesoscopic dynamic simulation system.

After the zones have been defined and the framework of the future model has been formed, it is necessary to proceed to the development of a system that allows simulating and describing the selected area. The general architecture of the developed model is based on the system for collecting data on the intensity and speed of movement from peripheral devices, the system for storing archived data on traffic flows, the system for predicting traffic flows in the road network, and the system for analyzing the effectiveness and quality of transport corridor management.

Joint coordinated work of the presented systems allows forming the dynamic correspondence matrices; creating special archives with data on previous studies; quickly evaluating the road network control quality using the results of computer simulation at the mesoscopic level; identifying the most effective transport corridor management strategies.

Figure 2 shows the general architecture of the real-time transport corridor mesoscopic model in ITS projects. 


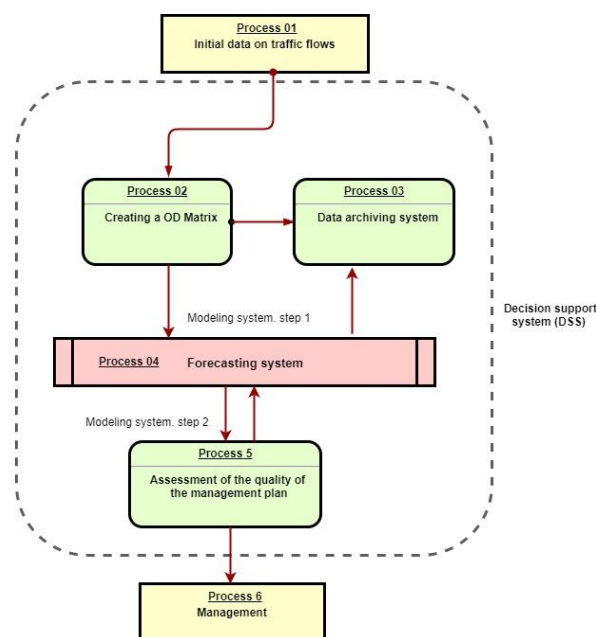

Fig. 2. The general architecture of the mesoscopic model of the realtime transport corridor in ITS projects.

Figure 3 shows the visualization of the transport mesoscopic model in the central part of Ryazan [20]. Figure a) Distribution of traffic intensity (vehicle/h) b) Speed distribution $(\mathrm{km} / \mathrm{h}) \mathrm{c}$ ) Density distribution (vehicle $/ \mathrm{km}) \mathrm{d}$ ) Timing speed contour $(\mathrm{km} / \mathrm{h})$.

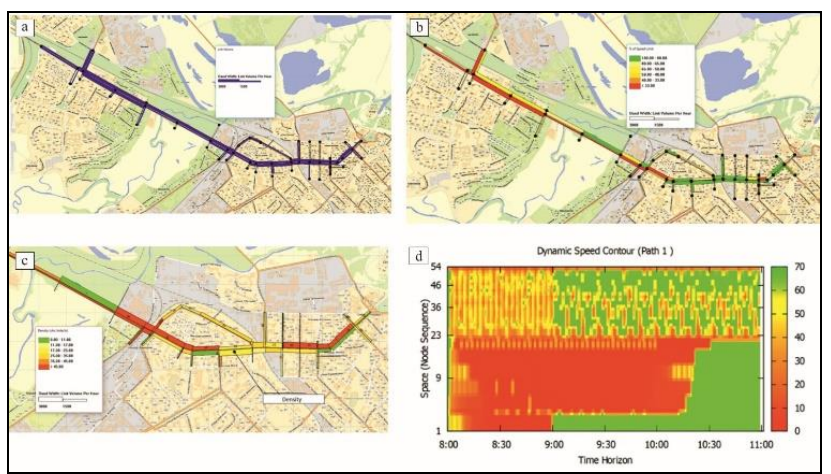

Fig. 3. Graphic presentation of calculation results in the mesoscopic model of the transport corridor in Ryazan.

In order to receive important information on real time traffic intensity, an additional data exchange flowchart was proposed. The general architecture of data processing and importing in the system is shown in Fig. 4.

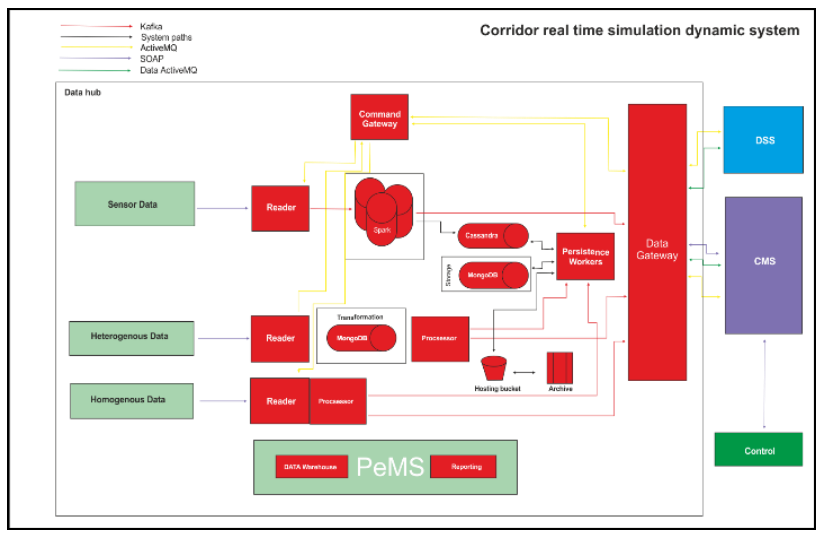

Fig. 4. General architecture for data processing and importing in the real-time traffic flow simulation system.

The proposed model allows to get the main macroindicators of traffic flows in the field of simulation, however, the calculation of some indicators featuring the reliability and performance of the ITS implementation area requires the use of additional metrics. Currently, scientists are solving the problem of the transport corridors performance within the framework of ITS projects. So, methods are being developed for searching and selecting a set of metrics [21] that feature the operation of the transport network [22]. The use of the following types of additional metrics is suggested.

Total vehicle mileage (VMT). This indicator characterizes the total distance traveled by all means of transport for a certain period of time within the ITS project implementation area. The indicator reflects the demand for the entire project implementation area as a whole. The indicator for a single segment can be calculated as follows:

$$
\operatorname{VMT}_{1}(t)=q_{i}(t) \Delta x_{l} \Delta t
$$

where $V M T_{1}(t)$ is the total distance traveled over one of the segments (1) for a certain simulation period (t);

$q_{i}(t)$ - vehicle traffic flow intensity for the simulation period $(t)$;

$\Delta x_{l}$ - a length of a certain segment of the network graph;

$\Delta t$ - time step of simulation.

To calculate the indicator in the total spatial-time domain (R), transform the formula (1):

$$
V M T_{R}(t)=\sum_{l . t e R} V M T_{l}(t)
$$

Total hours spent (VHT). The indicator allows to take into account the time spent in the ITS project operation area. For a single section of the road network, the following is calculated:

$$
V H T_{1}(t)=p_{i}(t) \Delta x_{l} \Delta t
$$

Where $p_{i}(t)$ - the total time spent taking into account the current traffic density within the section $(l)$ for the simulation period $(t)$.

To calculate the indicator in the total spatial-time domain (R), transform the formula (3):

$$
V H T_{R}(t)=\sum_{l . t e R} V H T_{l}(t)
$$

where $V H T_{R}(t)$ - The total number of hours spent in the entire spatial-time simulation domain for a certain simulation period $(t)$.

Network delay (ND). The indicator allows evaluating the additional loss of time compared with the movement time in free conditions. The network delay is calculated for a single section using the following formula: 


$$
N D_{l}(t)=V H T_{R}(t)-\frac{V M T_{l}(t)}{V_{l}},
$$

where $V_{l}$ - the movement time in free conditions.

For the spatial-time domain:

$$
N D_{R}=\sum_{l . t e R} D_{l}(t)
$$

Average network speed (AS). The indicator is calculated as a ratio of total mileage to total hours for the ITS project implementation area:

$$
A S_{R}=\frac{V M T_{R}}{V H T_{R}}
$$

The above indicators can be visualized in the additional software in order to develop a visual traffic flows forecast model.

\section{RESULTS}

The developed software package for visualizing the transport corridors performance serves as the basis for decision-making when managing the ITS project implementation area. The software package interface prototype is shown in Figure 5.

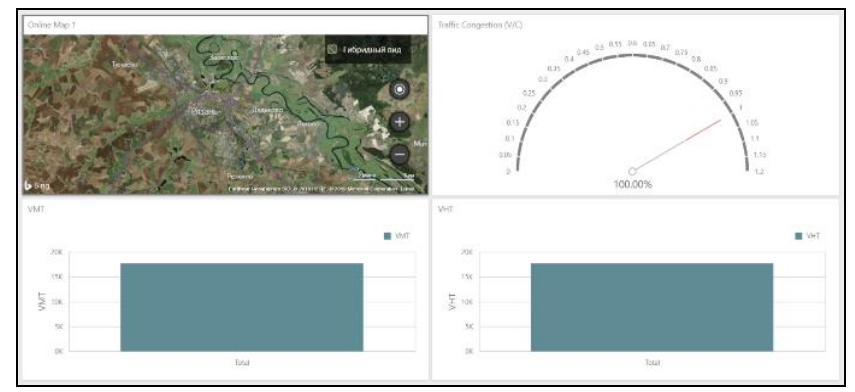

Fig. 5. The software package interface prototype for assessing the transport corridors performance as part of ITS projects.

The basis of this model is high-precision data relating to the traffic flow state obtained in the real time mode. Within the framework of the general methodology for model building, it is required to use the combined dynamic correspondence matrix [23]. This requirement is based on the need to forecast traffic flows and important parameters of the corridor operation (queues before intersections, dynamic travel time, density, etc.) in the real time mode, as well as to make correct short-term forecasts [24]. When calculating the dynamic matrix, two data sources are needed - data on the vehicle traffic intensity calculation and data on the traffic route [25]. For calculations, it is advisable to use induction sensors or video detectors [26]. To determine the paths in the matrices, it is proposed to use special sensors based on monitoring of the devices with Bluetooth and WiFi modules actuated. A prototype of such a device is currently being developed. Figure 6 shows the general diagram for operation of Bluetooth and WIFI devices monitoring system operation.

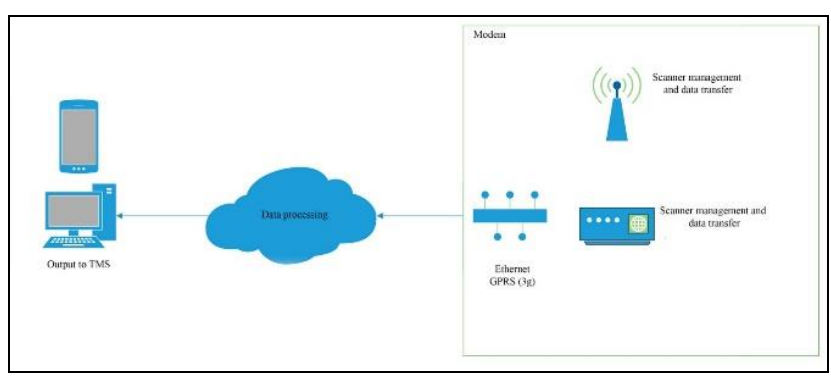

Fig. 6. The general diagram of Bluetooth and WIFI devices monitoring system operation.

The algorithm of Bluetooth and WiFi devices monitoring system operation is to constantly scan the vehicles flow, which is carried out at one or more points located at regulated intersections. The active scan coverage is $20 \mathrm{~m}$; the passive coverage is up to $50 \mathrm{~m}$ for Bluetooth and $\mathrm{WiFi}$. The data is transferred and stored with display of time and device number. The address data is stored in the local data storage for up to 30 days. The information is transmitted using the PPP protocol (LwIP stack); data processing and classification are carried out in a remote server. The addresses in the server are distributed as permanent (fixed signal sources that is present for more than 1 hour per day in the scanner coverage area), local (addresses that are already contained in the server database), non-local (addresses that are recorded for the first time and do not appear in the database more than 1 time per week). This function helps to determine a number of nonlocal and local vehicles and fixed access points.

As part of the transport corridor performance study in Ryazan, a series of simulation experiments were performed and respective estimates were obtained. The calculations of performance indicators for the central part of Ryazan are given in Table 1.

TABLE I. CALCULATIONS OF THE RYAZAN TRANSPORT CORRIDOR PERFORMANCE

\begin{tabular}{|c|c|}
\hline Indicators & $\begin{array}{c}\text { Morning peak period } \\
(\mathbf{0 8 : 0 0}-\mathbf{0 9 : 0 0} \text { a.m. })\end{array}$ \\
\hline Total mileage $\left(V M T_{R}\right)$ & 28978 \\
\hline Total hours spent $\left(V H T_{R}\right)$ & 1836 \\
\hline $\begin{array}{c}\text { Network delay }\left(N D_{R}\right) \\
\text { (seconds) }\end{array}$ & 69180 \\
\hline $\begin{array}{c}\text { Average network speed }\left(\mathrm{AS}_{\mathrm{R}}\right) \\
(\mathrm{km} / \text { hour })\end{array}$ & 15.7 \\
\hline
\end{tabular}

Low indicators $A S_{R}$ for the corridor under study indicate a lack of road network capacity. The optimal values of the network speed at which the highest network capacity is achieved are within the range of $30-40 \mathrm{~km} / \mathrm{h}$. Optimization of this indicator will improve the level of road users' service. Fundamentally, indicator $\mathrm{AS}_{\mathrm{R}}$ can be used as a key indicator in the operational planning of activities in the field of traffic within the ITS implementation areas.

Experimental estimates of the transport corridors operation performance confirmed the adequacy of the developed model, and the results obtained during the development study can be applied in the ITS projects in other cities. 


\section{SUMMARY}

The scientists are currently paying close attention to the transport corridors efficiency and reliability improvement. This fact is due to the congestion effects occur in the weakest places in terms of traffic capacity. The transport corridors effectiveness is also affected by accidental events that dramatically reduce the road network efficiency. In order to forecast the road network conditions, it is necessary to apply various methods for traffic flows simulation, as well as to use current achievements of microprocessor technology. The combination of simulation methods and traffic management, sensor technology will allow forming new synergetic systems for real-time road networks monitoring and control.

The practical experience of mesoscopic dynamic simulation of transport corridors in ITS projects is presented. The general architecture of the real-time transport corridor mesoscopic model in ITS projects is described. The paper presents the general concept for simulation zone selection when building the mesoscopic model of the real-time transport corridor and it offers the paths monitoring system based on scanning technology for devices with Bluetooth and WIFI actuated. The presented results can be used when developing the simulation subsystems in ITS projects. The use of the above study results allows expanding the existing systems and approaches to decision-making in the field of traffic management and ITS development.

\section{ACKNOWLEDGMENT}

The article was prepared as part of the work on the grant of the President of the Russian Federation NSh-4028.2018.6

\section{REFERENCES}

[1] S.V. Zhankaziev, Intelligent transport systems: training aids, Moscow: MADI, 2016, p. 120.

[2] V.V. Komarov, S.A. Garagan, Architecture and standardization of telematic and intelligent transport systems. Foreign experience and domestic practice, Moscow: Science and Research Library "ENERGY", 2012, p. 325.

[3] D. Wolf and O. Yakovenko, PTV Optima - Real-time transport situations forecast for cities and megacities, System analysis and logistics, 2014, No. 11

[4] M. Lighthill, G. Whitham, On kinematic waves II: a theory of traffic flow on long crowded roads, Proc. Royal Society of London, Part A 229 (1178), 1955, pp. 317-345.

[5] G. F. Newell, A simplified theory on kinematic waves in highway traffic, part I: general theory, Transportation Research, Part B, vol. 27(4), 1993, pp. 281-287.

[6] G. F. Newell, A simplified theory on kinematic waves in highway traffic, part II: queueing at freeway bottlenecks, Transportation Research, Part B, vol. 27(4), 1993, pp. 289-303.

[7] G. F. Newell, A simplified theory on kinematic waves in highway traffic, part III: multi-destination flows, Transportation Research, Part B, vol. 27(4), 1993, pp. 305-313.

[8] X. Zhou, H.S. Mahmassani and K. Zhang, Dynamic Microassignment Modeling Approach for Integrated Multimodal Urban Corridor Management, Transportation Research, Part C, 16, No. 2, 2008, pp. 167-186.
[9] X. Zhou and H. S. Mahmassani, A Structural State Space Model for Real-Time Origin-Destination Demand Estimation and Prediction in a Day-to-Day Updating Framework, Transportation Research, Part B, 41(8), 2007, pp. 823-840.

[10] O.Y. Iliashenko, A.I. Levina, A. Dubgorn. Using business intelligence technologies for evaluation of road network organization (2017) Proceedings of the 30th International Business Information Management Association Conference, IBIMA 2017, pp. 2144-2155.

[11] V.V. Zyryanov, Methods for assessment of simulation results adequacy, Don Engineering Bulletin, Vol. 25(2), 2013, pp. 132-137.

[12] V.V. Zyryanov, V.G. Kocherga and A.A. Feofilova, Application of models for movement route selection when forecasting the traffic flows distribution on the designed road network, Actual problems of roads design: Proceedings of JSC GiprodorNII, No. 4(63), 2013, pp. $33-40$.

[13] V.V. Zyryanov, Traffic incidents identification methods. Scientific Review (Nauchnoe Obozrenie), No. 10-3, 2014, pp. 807-810.

[14] S.V. Zhankaziev and R.F. Khalilev, Principles for formation of the local project architecture of the intelligent transport system, Motor Transport Enterprise, No. 12, 2012.

[15] S.V. Zhankaziev, A.M. Ivanov and V.M. Vlasov, Scientific approaches to the formation of the ITS building concept in Russia, Motor Transport Enterprise, No. 4, 2010.

[16] N.N.N. Azlan and M.M. Rohani, Overview of Application of Traffic Simulation Model. In Proceedings of the Malaysian Technical Universities Conference on Engineering and Technology (MUCET 2017), Penang, Malaysia, 6-7 December 2017, pp. 1-6.

[17] A. Pell, A. Meingast and O. Schauer, "Trends in real-time traffic simulation," Transportation Research Procedia, vol. 25, 2017, pp. 1477-1484.

[18] A. Attanasi, L. Meschini, M. Pezzulla, G. Fusco, G. Gentile, and N. Isaenko, "A hybrid method for real-time short-term predictions of traffic flows in urban areas," 5th IEEE International Conference on Models and Technologies for Intelligent Transportation Systems (MTITS), 2017, pp. 878-883.

[19] Aimsun.live, https://www.aimsun.com/aimsun-live/papers

[20] A. Kuraksin, A. Shemyakin and S. Borychev, Meso-DTA traffic model technology for evaluating effectiveness and quality of the organization of traffic in large cities, Transportation Researh Procedia, 12th International Conference «Organization and Traffic Safety Management in large cities», SPbOTSIC-2016, 28-30 September 2016, St. Petersburg, Russia, 2017, p. 378-383.

[21] J. A. Bonneson, A. Sharma and D. Bullock, Measuring the Performance of Automobile Traffic on Urban Streets. Final Report, NCHRP 3-79, 2007

[22] C. M. Day and D. Bullock, Arterial Performance Measures, Volume 1: Performance Based Management of Arterial Traffic Signal Systems. Final Report, NCHRP 3-79A, vol. 1, 2010.

[23] S. Bera and K. V. Krisha Rao, Estimation of origin-destination matrix from traffic counts: the state of the art, European Transport, vol. 49, 2011 , pp. 3-23.

[24] C. M. Day, E. J. Smaglik, D. M. Bullock and J. R. Sturdevant, RealTime Arterial Traffic Signal Performance Measures. Publication FHWA/IN/JTRP-2008/09, Joint Transportation Research Program, Indiana Department of Transportation and Purdue University, West Lafayette, Indiana, 2008.

[25] C-C. Lu, X. Zhou and K. Zhang, Dynamic Origin-Destination Demand Flow Estimation under Congested Traffic Conditions, Transportation Research, Part C, 34, 2013, pp. 16-37.

[26] X. Zhou and G. List, An Information-Theoretic Sensor Location Model for Traffic Origin-Destination Demand Estimation Applications, Transportation Science, 44, 2010, pp. 254-273. 